\title{
CROWBAR RESISTANCE SETTING AND ITS INFLUENCE ON DFIG LOW VOLTAGE RIDE THROUGH
}

\author{
Shengqing Li, ${ }^{*}$ Yao Ming, ${ }^{*}$ Yuwen Zhang, ${ }^{*}$ and Wenfeng $\mathrm{Wu}^{*}$
}

\begin{abstract}
Doubly-fed induction generator (DFIG) often adopts a crowbar protective circuit to realize low-voltage ride through (LVRT) under low-voltage fault of the grid. Crowbar resistance will affect the LVRT effect of the unit significantly. Time domain expression of transient current of the wind turbine generator system under the voltage drop fault and the calculation formula of fault current at the rotor side were deduced through space vector analysis and Laplace transformation based on the transient mathematical model of the DFIG system under voltage drop. A crowbar resistance adjustment method conforming to engineering practices was proposed, which overcame the overcurrent at the rotor side and overvoltage of the DC bus after the crowbar protective circuit is applied. The case study and the simulation test demonstrated that the proposed method inhibits the transient fault current component effectively and can increase the automation level of the DFIG system.
\end{abstract}

\section{Key Words}

Doubly-fed induction generator, low-voltage ride through, voltage drop, crowbar circuit, automation level

\section{Introduction}

Energy crisis and environmental protection are the two big problems that human beings are facing. To address these two issues, the development of renewable energies has attracted unprecedented attention from countries in the world. New renewable energy sources include solar energy, wind energy, geothermal energy, tidal energy, biomass energy and so on. Among them, wind energy is an inexhaustible and clean energy source, also is the cheapest and most potential "green energy source", which has been widely developed and utilized around the world.

In view of continuous wind power development, countries with developed wind power industry have reached an agreement on grid specifications to reduce or eliminate adverse impacts caused by offline operation of the unit: wind turbine generators under networking operation are

* College of Electrical and Information Engineering, Hunan University of Industry, ZhuZhou, China; e-mail: lsq1961@ sohu.com, mingyao003@163.com, zhangyuwen0124@qq.com, wuwenfeng1992@163.com

Recommended by Prof. Anmin Zhu

(DOI: 10.2316/Journal.206.2017.6.206-5110) not allowed to run offline under voltage fault in a certain amplitude and time of duration. In other words, all wind turbine generators must have low-voltage ride through (LVRT) ability, provide voltage-frequency-coordinated control and help voltage recovery of the fault grid when necessary. Many developed countries have formulated technical norms on LVRT of the wind turbine generator system in the power grid according to practical situations. They are improving LVRT of the wind turbine generator system continuously based on practical running conditions. Therefore, LVRT technology has become one of the key technologies for large-scaled connection of wind power grids.

Scholars have made many related studies and proposed some solutions. In [1]-[4], dynamic characteristics of the stator and rotor currents of doubly-fed induction generator (DFIG) after the crowbar protective circuit was applied at the rotor side were analysed from the perspective of time domain, whose results were compared with simulation results. In [5]-[10], expressions of stator and rotor currents of DFIG under parallel operation after the symmetrical shortcircuit at the generator terminal in the static coordinates were deduced and resistance of the crowbar protective circuit was adjusted preliminarily on the basis of the deduced rotor current expression. Although these expressions have complicated structure, they have been applied successfully in engineering practices. In [11]-[14], the expression of rotor current of DFIG under parallel operation after threephase short circuit at the generator terminal was inferred from the perspective of flux linkage. Influences of crowbar resistance, input and exit time on dynamic characteristics of LVRT of DFIG were discussed roughly. In [15]-[35], applications of neural network control in the wind turbine generator system were studied. By analysing the change of output power caused by up-down features, wind speed is labelled by the features in every moment to increasing the training dimensions and then the prediction accuracy is improved. The artificial neural network can approximate nonlinear mapping of any nonlinear models and be used to design adaptive controllers based on its learning and selfconvergence, thus enabling it to increase system control accuracy and enhance system adaptation to the environment. Fuzzy neural network control could be designed by combining neural network control and fuzzy control to 
control the wind turbine generator system. However, it is difficult to be applied in a large scale due to the complicated design of the control system and difficult parameter calibrations.

In this paper, the time domain expression of transient current of the wind turbine generator system under the voltage drop fault and the calculation formula of fault current at the rotor side were deduced through space vector analysis and Laplace transformation based on the transient mathematical model of the DFIG system under voltage drop. In this paper, the method of crowbar resistance adjustment conforming to engineering practices was proposed, which overcame the overcurrent at the rotor side and overvoltage of the DC bus after the crowbar protective circuit was made use of. Both case study and the simulation test demonstrated that the proposed method is simple and can increase the automation level of the DFIG system.

\section{Steady-state Mathematical Model of DFIG Wind Power System}

The topological structure of a DFIG wind turbine with crowbar protection circuit is shown in Fig. 1.

The mathematical model of DFIG in the two-phase synchronous rotating reference frame could be gained through the coordinate transformation of mathematical models in the three-phase static coordinates. As axes $d$ and $q$ are perpendicular mutually and there is no magnetic coupling between two-phase winding, the mathematical model of DFIG is simplified significantly, which is convenient to analyse voltage drop fault.

For the DFIG voltage equation [36]:

$$
\left\{\begin{array}{l}
u_{s d}=R_{s} i_{s d}-\omega_{1} \psi_{s q}+\frac{d \psi_{s d}}{d t} \\
u_{s q}=R_{s} i_{s q}+\omega_{1} \psi_{s d}+\frac{d \psi_{s q}}{d t} \\
u_{r d}=R_{r} i_{r d}-\omega_{s} \psi_{r q}+\frac{d \psi_{r d}}{d t} \\
u_{r q}=R_{r} i_{r q}+\omega_{s} \psi_{r d}+\frac{d \psi_{r q}}{d t}
\end{array}\right.
$$

where $u_{s d}, u_{s q}, u_{r d}, u_{r q}$ are voltage components of the stator, rotor, axis $d$ and axis $q ; i_{s d}, i_{s q}, i_{r d}, i_{r q}$ are current components of the stator, rotor, axis $\mathrm{d}$ and axis $\mathrm{q} ; \psi_{s d}$, $\psi_{s q}, \psi_{r d}, \psi_{r q}$ are flux components of the stator, rotor, axis $d$ and axis $q ; \omega_{s 1}$ is the slip angular velocity, $\omega_{s 1}=\omega_{e}-\omega_{r}$.

For the DFIG flux equation [36]:

$$
\left\{\begin{array}{l}
\psi_{s d}=L_{s} i_{s d}+L_{m} i_{r d} \\
\psi_{s q}=L_{s} i_{s q}+L_{m} i_{r q} \\
\psi_{r d}=L_{m} i_{s d}+L_{r} i_{r d} \\
\psi_{r q}=L_{m} i_{s q}+L_{r} i_{r q}
\end{array}\right.
$$

where $L_{m}$ is the equivalent mutual inductance between stator winding and rotor winding in the synchronous coordinate system, $L_{m}=1.5 L_{s m} ; L_{s}$ and $L_{r}$ are the selfinductance of the stator and rotor, $L_{s}=L_{\sigma s}+L_{m}$ and $L_{r}=L_{\sigma r}+L_{m}$.

\section{Transient Analysis under Voltage Drop at Generator Terminal of DFIG}

Transient mathematical expressions of stator voltage and rotor current of DFIG under voltage drop fault have to be deduced when discussing influences of voltage drop on the DFIG system. On the occasion of voltage drop of grids, DFIG's rotor circuit is usually shorted by the crowbar circuit, so we can make use of the principle of circuit stacking to obtain the expression of the DFIG transient current in this case. The drop process of stator three-phase voltage in the case of low-voltage fault can be equivalent to that of the increase in amplitude in the stator side that is opposite to the voltage of the original side but the same as its amplitude.

The space vector of the stator short-circuit current was set:

$$
i_{s}=i_{s 0}+i_{s 1}
$$

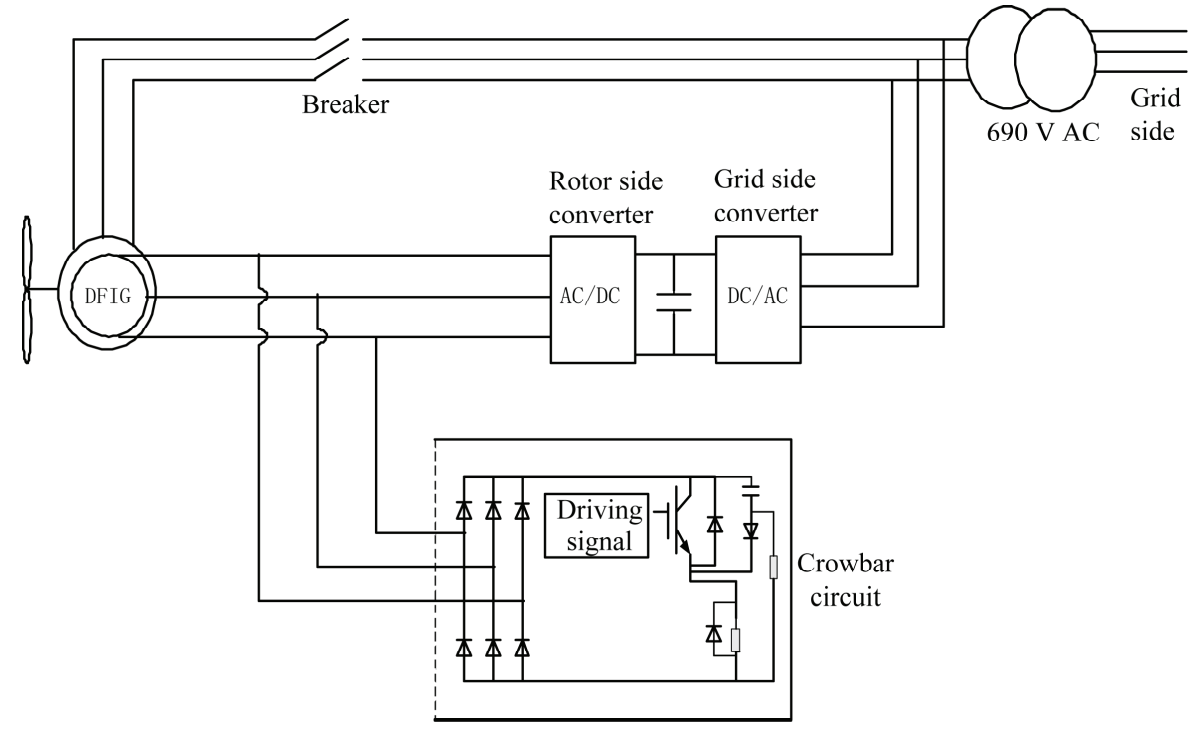

Figure 1. DFIG wind turbine with crowbar protection circuit. 
where $i_{s 0}$ is the space vector of stator steady-state current before the stator voltage drop fault and $i_{s 1}$ is the space vector of stator current produced by the opposite threephase voltage that is applied suddenly at the stator side.

If the space vector of stator voltage is $u_{s}=$ $-j U_{m} e^{j\left(\omega_{1} t+\varphi\right)}$, while it is $u_{s}^{\prime}=-j U_{m} e^{j\left(\omega_{s} t+\varphi\right)}$ in the rotor coordinate system. Therefore, the space vector $i_{s 0}^{\prime}$ of current before the stator voltage drop is

$$
i_{s 0}^{\prime}=\frac{u_{s}^{\prime}}{R_{s}+j \omega_{1} L_{s}}=\frac{-j U_{m} e^{j\left(\omega_{s} t+\varphi\right)}}{R_{s}+j X_{s}}
$$

where $X_{s}$ is the stator reactance, $R_{s}$ is the stator resistance, $\omega_{1}$ is the synchronous rotational angular velocity of stator and $\omega_{s}$ is the angular velocity of slip frequency.

In the rotor coordinate system, the initial flux linkages of stator and rotor were set 0 . The $s$-domain expression of stator voltage equation could be gained through Laplace transformation:

$$
A U_{s 1}^{\prime}=\left[R_{s}+\left(s+j \omega_{1}\right) L_{s}(s)\right] I_{s 1}^{\prime}
$$

In the type, where $A$ is the degree of voltage drop $(0<A<1)$ and $L_{s}(s)$ is the operation inductance at the stator side in the rotor coordinate system: $L_{s}(s)=L_{s}\left(1+s T_{r}^{\prime}\right) /\left(1+s T_{r}\right)$.

Then, the stator current could be gained:

$$
I_{s 1}^{\prime}=\frac{j A U_{m} e^{j \varphi}}{\left(s-j \omega_{s}\right)\left(\alpha+s+j \omega_{1}\right) L_{s}(s)}
$$

Equation (6) was extended into partial fraction and $i_{s 1}^{\prime}$ could be gained through its Laplace inverse transformation. Considering $\omega_{r} \gg \alpha,-1 / T_{r}^{\prime}+\alpha \ll \omega_{r}$ and $\left(s-j \omega_{s}\right)\left(\alpha+s+j \omega_{1}\right) \approx s\left(\alpha+s+j \omega_{r}\right)$, it can get $i_{s 1}^{\prime}$ :

$$
\begin{aligned}
i_{s 1}^{\prime} \approx & \frac{A U_{m} e^{j\left(\omega_{s} t+\varphi\right)}}{X_{s}}\left[1-e^{-\left(\alpha+j \omega_{1}+j \omega_{s}\right) t}\right] \\
& +A U_{m} e^{j \varphi}\left(\frac{1}{X_{s}^{\prime}}-\frac{1}{X_{s}}\right)\left[e^{-t / T_{r}^{\prime}}-e^{-\left(\alpha+j \omega_{r}\right) t}\right]
\end{aligned}
$$

Under empty or slight load of DFIG, it is believed basically that $\omega_{r} \approx \omega_{1}$. Then, $i_{s}^{\prime}$ is acquired. Finally, the time domain expression of space vector of stator current in the stator coordinate system could be gained:

$$
\begin{aligned}
i_{s}= & i_{s}^{\prime} e^{j \omega_{r} t}=(A-1) \frac{U_{m} e^{j\left(\omega_{1} t+\varphi\right)}}{X_{s}}-\frac{A U_{m} e^{j \varphi}}{X_{s}^{\prime}} e^{-t \alpha} \\
& +A U_{m} e^{j \varphi}\left(\frac{1}{X_{s}^{\prime}}-\frac{1}{X_{s}}\right) e^{-t / T_{r}^{\prime}} e^{j t \omega_{r}}
\end{aligned}
$$

Then, the $A$-phase current of stator $\left(i_{A}\right)$ is:

$$
\begin{aligned}
i_{A}= & \operatorname{Re}\left(i_{s}\right)=(A-1) \frac{U_{m}}{X_{s}} \cos \left(\omega_{1} t+\varphi\right)-\frac{A U_{m}}{X_{s}^{\prime}} e^{-\alpha t} \cos \varphi \\
& +A U_{m}\left(\frac{1}{X_{s}^{\prime}}-\frac{1}{X_{s}}\right) e^{-\alpha t} \cos \left(\omega_{r} t+\varphi\right)
\end{aligned}
$$

It can be known from (9) that stator current is composed of $(A-1) U_{m} \cos \left(\omega_{1} t+\varphi\right) / X_{s}, A U_{m} e^{-\alpha t} \cos \varphi / X_{s}^{\prime}$ and $A U_{m}\left(1 / X_{s}^{\prime}-1 / X_{s}\right) e^{-t / T_{r}^{\prime}} \cos \left(\omega_{r} t+\varphi\right) \cdot(A-1) U_{m} \cos \left(\omega_{1} t+\right.$ $\varphi) / X_{s}$ is the steady-state component of stator current, which is determined by the degree of voltage drop (A). $A U_{m} e^{-\alpha t} \cos \varphi / X_{s}^{\prime}$ is the DC component of transient fault current, which relies on the phase angle $(\varphi)$ at short circuit. It attenuates continuously at the stator time constant $\left(T_{a}, T_{a}=1 / \alpha\right) . A U_{m}\left(1 / X_{s}^{\prime}-1 / X_{s}\right) e^{-t / T_{r}^{\prime}} \cos \left(\omega_{r} t+\varphi\right)$ is the AC component and accounts for most of transient current. It attenuates at the transient time constant $\left(T_{r}^{\prime}\right)$.

\section{Selection of Crowbar Resistance and Case Study}

Applying crowbar protective circuit at the rotor side can increase rotor resistance of the generator at voltage drop fault and inhibit AC component in transient fault current effectively, thus preventing DFIG system from offline operation under low-voltage fault. However, improper protective resistance in the Crowbar circuit may cause voltage pump rise on the DC bus of the converter. It is necessary to choose appropriate resistance. For this reason, the time domain expression of current at the rotor side at voltage drop shall be calculated.

\subsection{Selection of Crowbar Resistance}

According to the relationship between voltage and current of stator and rotor, the time domain expression of fault current at the rotor side could be gained after transformation of rotational coordinates:

$$
\begin{aligned}
i_{r}^{\prime}= & \frac{1}{j\left(L_{s} L_{r}-L_{m}\right)}\left[\frac{L_{s}}{s} \sqrt{u_{d r}^{2}+u_{q r}^{2}} e^{j \delta t}+L_{m} U_{s}\right] e^{-t / T_{r}^{\prime}} \\
& +\frac{U_{s}}{j \omega_{s}}\left[-\frac{L_{m} e^{-j(1-s) \omega_{s} t} e^{-t / T_{s}^{\prime}}}{\left(L_{2}+L_{m}\right) L_{s}^{\prime}}+\frac{e^{-t / T_{r}^{\prime}}}{L_{r}^{\prime}}\right]
\end{aligned}
$$

Similar to A-phase current of stator, fault current at the rotor side is composed of three components with different frequencies: the first component is the slip ratio current, which is corresponding to the steady-state current after shutting inverter at the rotor side and inputting crowbar protective circuit and rotor current upon the voltage drop fault. The second one is the steady-state rotational frequency current of the rotor. Rotational speed could not be changed timely at short-circuit fault. It can be viewed as still rotating at the rate of $\omega_{r}$ and induced DC component in stator produces a static magnetic field in the space that will cut rotors at the rotational frequency and induce current component with equivalent frequency. This current component attenuates according to the attenuation parameter determined by stator parameters. The third component is the attenuating DC component, which reflects attenuating DC component in rotor flux in rotor winding.

It can be known from (10) that $r_{c}$ in the crowbar protective circuit is crucial to inhibit transient rotor current. It is negatively associated with current under low-voltage fault as well as the natural power and torque vibration. 
Nevertheless, over high $r_{c}$ will bring overvoltage of the grid-side converter and rotor winding, finally resulting in voltage pump rise on the DC bus and intensifying generator vibration.

Then, the calculation method of maximum fault current at the rotor side and the adjustment method of crowbar resistance could be gained:

(1) After the application of crowbar protective circuit, the maximum fault current at the rotor side shall be smaller than the safety value of rotor current $\left(I_{f m}\right)$. Generally speaking, $I_{f m}$ was determined by 1.5 p.u. Therefore,

$$
\frac{U_{s}}{\sqrt{X_{L}^{2}+\left(r_{c}+R_{r}\right)^{2}}} \leq K_{I} I_{f m} .
$$

Hence, the minimum $r_{c}$ could be calculated. In (11), $X_{L}=\omega_{1} L_{s}$, where $\omega_{1}$ is synchronous rotational angular velocity of stator, $L_{s}$ is operational inductance at the stator side in the rotor coordinates, $R_{r}$ is equivalent resistance at the rotor side, and $K_{I}$ is the safety factor of rotor current $\left(K_{I}=0.9-1.2\right)$. On the occasion of voltage drop occurs at the generator terminal, $K_{I}=1.2$. Voltage drop occurs at the user side, $K_{I}=0.9$.

(2) To prevent overvoltage on the DC bus after the application of crowbar protective circuit, the voltage drop of the crowbar protective circuit must be smaller than the threshold voltage $U_{d c m}$ :

$$
\frac{\sqrt{3} r_{c} U_{s}}{\sqrt{X_{L}^{2}+\left(r_{c}+R_{r}\right)^{2}}} \leq K_{U} U_{d c m}
$$

The maximum $r_{c}$ in the adjustment range could be gained. In (12), $K_{U}$ is the safety factor of bus voltage $\left(K_{U}=0.95-1.3\right) . K_{U}=1.3$ on the occasion of voltage drop occurs at the generator terminal, but $K_{U}=0.95$ when voltage drop occurs is at the user side.

(3) The range of $r_{c}$ value can be obtained from the above two types:

$$
\left\{\begin{array}{l}
r_{c_{-} \max } \leq \frac{K_{U} U_{d c m} X_{L}}{\sqrt{3 U_{s}^{2}-U_{d c}^{2}}-R_{r}} \\
r_{c_{-} \min } \geq \sqrt{\left(\frac{U_{S}}{K_{I} I_{f m}}\right)^{2}-X_{L}^{2}}-R_{r}
\end{array}\right.
$$

The reasonable range of $r_{c}$ could be gained from (13). To inhibit overcurrent at the rotor side and prevent overvoltage on the grid-side converter, appropriately larger of crowbar resistance in the reasonable range will contribute better to the LVRT effect of the DFIG system.

\subsection{The Example Analysis}

To determine the appropriate resistance of crowbar circuit in a 2-MW DFIG, different maximum short-circuit currents $\left(I_{r \max }\right)$, corresponding rotor voltage $\left(U_{r \max }\right)$ and the
Table 1

Calculation Results of $I_{r \max }, U_{r \max }$ and $Q_{s \max }$ under Different Crowbar Resistances

\begin{tabular}{|l|c|c|c|}
\hline$r_{c}$ & $I_{r \max }$ & $U_{r \max }$ & $Q_{s \max }$ \\
\hline 0.01 & 8.86 & 0.081 & -1.51 \\
\hline 0.03 & 7.92 & 0.161 & -1.65 \\
\hline 0.05 & 6.89 & 0.345 & -1.77 \\
\hline 0.07 & 6.15 & 0.490 & -1.86 \\
\hline 0.09 & 5.98 & 0.535 & -2.05 \\
\hline 0.10 & 5.77 & 0.577 & -2.18 \\
\hline
\end{tabular}

peak of stator reactive power $\left(Q_{s \max }\right)$ could be gained by bringing $r_{c}$ into (10). Specific calculated results are listed in Table 1.

It can be seen from Table 1 that $U_{r \max }$ decreases with the increase of $r_{c}$, while the maximum voltage at the rotor side increases. To avoid overvoltage at the DC side, the maximum rotor voltage shall be $U_{r \max }<U_{r \text { lim }}$, where $U_{r \lim }$ is the maximum voltage that can be sustained by the grid side converter. It is a parameter related to the performance of the converter itself and generally marked on the nameplate. For the 2MW DFIG used in this paper, $U_{r \lim }=0.570$. However, it can be seen from Table 1 that $U_{r \max }<U_{r \text { lim }}$ is no longer established when the $r_{c}=0.10$ indicate that the crowbar resistance should not exceed 0.095. In general, in the adjustment of crowbar resistance, higher $r_{c}$ could inhibit overcurrent at the rotor side better.

\section{Simulation and Experimental Analysis}

A MATLAB/Simulink simulation and the low power test system were built in the laboratory, to test low voltage of DFIG on the functional and the reasonable range of the crowbar resistance.

\subsection{Simulation Analysis}

To verify reasonability of the above-adjusted crowbar resistance, rotor current $\left(I_{r}\right)$, stator reactive power $\left(Q_{s}\right)$ and generator terminal voltage $\left(U_{s}\right)$ after the application of crowbar protective circuit were simulated when $r_{c}$ is 0.075 and 0.085 through combining with the case study results. Results are shown in Fig. 2. When $r_{c}=0.075$ after the fault, the maximum $I_{r}$ is 4.15 , but $I_{r}$ is about 3.80 when $r_{c}=0.085$ and the rotor current could be stabilized more quickly after troubleshooting. The simulation result is very close to the calculated result. After low-voltage fault is eliminated; the maximum instant stator reactive powers of DFIG absorbed from the grid are 1.85 and 3.00. Smaller crowbar resistance is accompanied with higher current in the rotor transient process, which requires to supply the system with larger reactive power in early fault period. On the contrary, larger resistance will inhibit power oscillation during the fault period. Based on case study and simulation analysis, it is suggested that crowbar resistance 

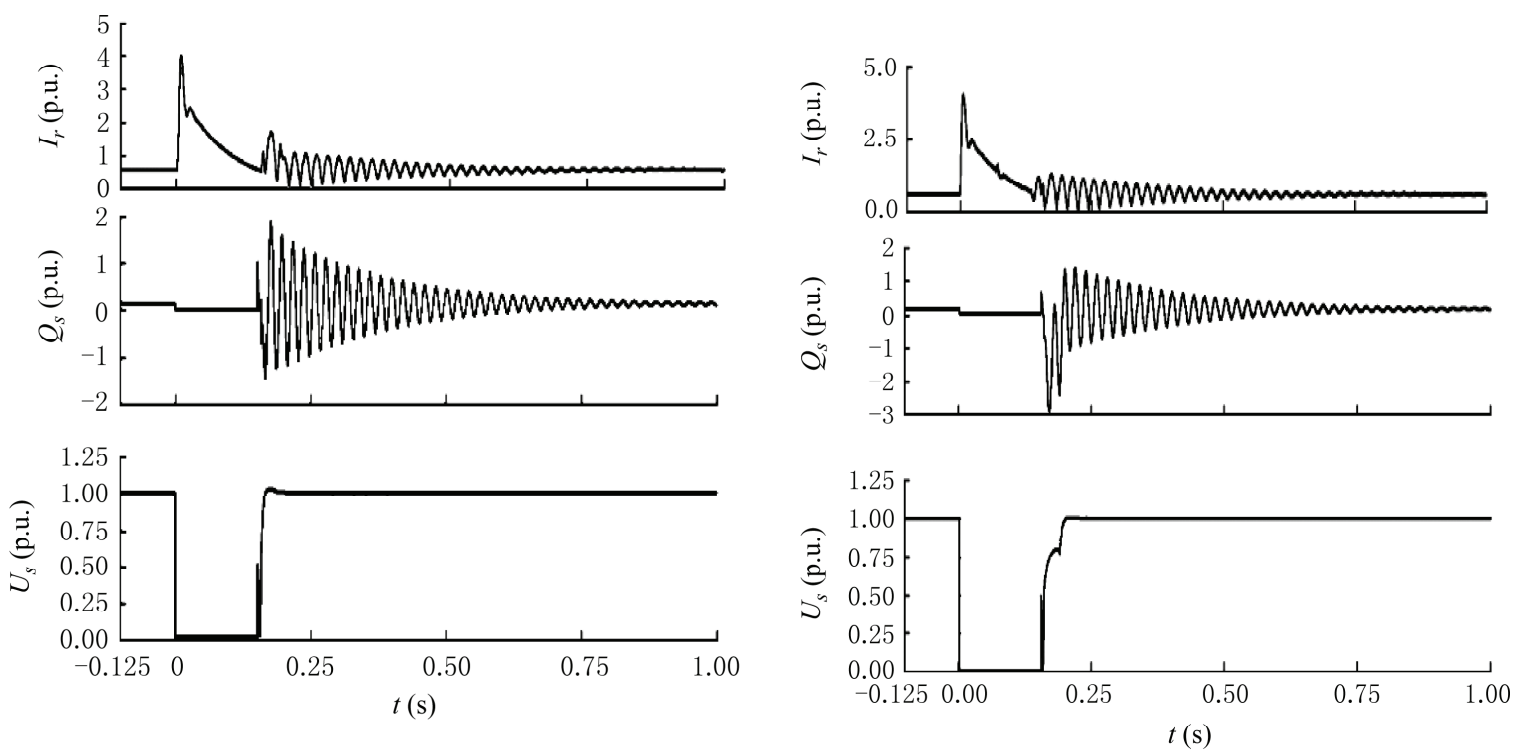

(a)

(b)

Figure 2. The simulation results of $I_{r}, U_{s}$ and $Q_{s}$ under different crowbar resistances: (a) $r_{c}=0.075$, (b) $r_{c}=0.085$.

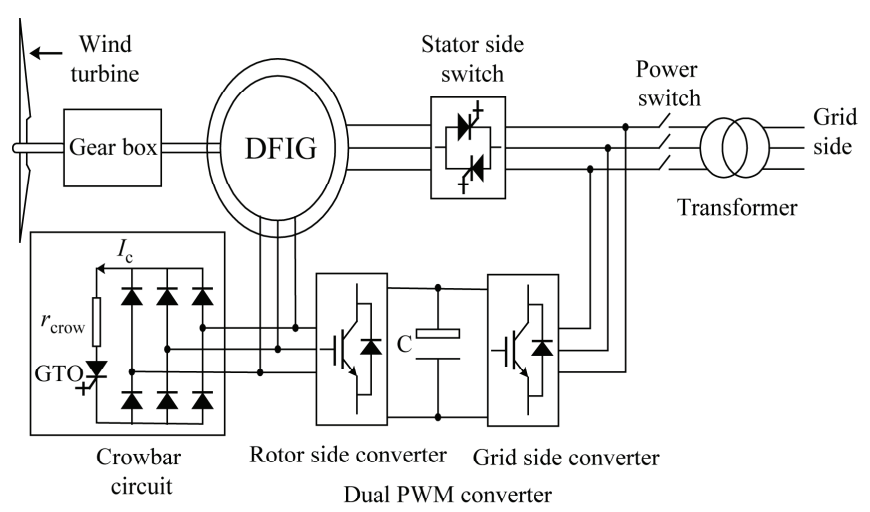

Figure 3. The main circuit of the system.

shall be as high as possible in practical engineering while ensuring the effective inhibition of rotor overcurrent.

\subsection{Experimental Verification}

To verify reasonability of simulation and case analysis results, a small power test system with a rated power of $10 \mathrm{~kW}$ was constructed to test reasonability of different crowbar resistances. Different crowbar resistances were used in the experiment. The main circuit of the system is shown in Fig. 3 and the DFIG parameters are revealed in Table 2.

In Fig. 3, the generator stator side connects the grid side through a boost transformer; the rotor side is associated with the dual pulse width modulation (PWM) converter when the voltage is normal but with the crowbar protection resistance when fault occurs. The protection resistance could be input and removed by the control of the gate turn off thyristor (GTO).

This experiment involved six crowbar resistances: $r_{c}=0.085,0.086,0.087,0.088,0.089$ and 0.090. Experimental results of $I_{r \max }, U_{r \max }$ and $Q_{s \max }$ are presented in Table 3.
Table 2

$10 \mathrm{~kW}$ DFIG Parameters

\begin{tabular}{|l|c|c|}
\hline Parameter & Value & $\begin{array}{c}\text { Conversion of the } \\
\text { Unitary Value }\end{array}$ \\
\hline $\begin{array}{l}\text { The stator line } \\
\text { voltage } U / \mathrm{V}\end{array}$ & 380 & 1 \\
\hline $\begin{array}{l}\text { Stator resistance } \\
R / \Omega\end{array}$ & 0.1050 & 0.0073 \\
\hline $\begin{array}{l}\text { Rotor resistance } \\
R / \Omega\end{array}$ & 0.1050 & 0.0073 \\
\hline $\begin{array}{l}\text { Stator leakage } \\
\text { inductance } L / \mathrm{H}\end{array}$ & 0.0032 & 0.0680 \\
\hline $\begin{array}{l}\text { Rotor leakage } \\
\text { inductance } L / \mathrm{H}\end{array}$ & 0.0034 & 0.7320 \\
\hline $\begin{array}{l}\text { Mutual } \\
\text { Inductance } L / \mathrm{H}\end{array}$ & 0.2100 & 0.0146 \\
\hline
\end{tabular}

Table 3

The Experimental Results of $I_{r \max }, U_{r \max }$ and $Q_{s \max }$ under Different Crowbar Values

\begin{tabular}{|l|c|c|r|}
\hline$r_{c}$ & $I_{r \max }$ & $U_{r \max }$ & $Q_{s \max }$ \\
\hline 0.085 & 6.13 & 0.505 & -1.975 \\
\hline 0.086 & 6.11 & 0.522 & -1.982 \\
\hline 0.087 & 6.09 & 0.547 & -1.998 \\
\hline 0.088 & 6.08 & 0.558 & -2.050 \\
\hline 0.089 & 6.06 & 0.562 & -2.150 \\
\hline 0.090 & 6.04 & 0.565 & -2.202 \\
\hline
\end{tabular}


According to the comparison between data in Tables 1 and 3, DFIG parameters change consistently under different crowbar resistances. Simulation results and experimental results could verify mutually, thus confirming that higher crowbar resistance in the reasonable range can inhibit rotor overcurrent better.

\section{Conclusion}

In this paper, transient characteristics of the DFIG system under voltage drop fault at the generator terminal are analysed by Laplace transformation from the perspective of space vector. Applying the crowbar protective circuit into the rotor side can increase generator rotor resistance at voltage drop fault of the grid and avoid voltage pump rise of the DC bus, thus enabling it to inhibit transient fault current effectively. Considering the intensive changes of electrical parameters and mechanical quantities in the fault transient process, crowbar resistance should not be too small to weaken electromagnetic torque vibration in the fault period and decrease damages of mechanical drive in the DFIG system. In a reasonable range of value, higher crowbar resistance is conducive to inhibit rotor overcurrent better.

\section{Acknowledgement}

The authors would like to thank the anonymous reviewers and the editors for their helpful suggestions and comments for improving quality of this paper.

\section{References}

[1] F. Wang and J. Jiang, Wind power with a dual PWM converter control strategy of the power balance of joint research, Proceedings of the CSEE, 26(22), 2006, 134-139.

[2] Y. She, W. Jiang, C. Kan, et al., An optimization control system of back-to-back front-end rectifier under unbalanced grid, Proceedings of the CSEE, 35(09), 2015, 2261-2271.

[3] Y. Chi, W. Wang, and H. Dai, Improve grid wind farms based on doubly-fed induction generator transient voltage stability study, Proceedings of the CSEE, 25(27), 2007, 25-31.

[4] F. Nagata, K. Kuribayashi, K. Kiguchi, and K. Watanabe, Simulation of fine gain tuning using genetic algorithms for model-based robotic servo controllers, Proc. IEEE Int. Symp. Computational Intelligence in Robotics and Automation, IEEE, Jacksonville, USA, 2007, 196-201.

[5] Y.Y. Wu and Y.Q. Wu, Stability analysis for recurrent neural networks with time-varying delay, International Journal of Automation and Computing, 6(3), 2009, 223-227.

[6] J.C. Zagal and J. Ruiz-del-Solar, Combining simulation and reality in evolutionary robotics, Journal of Intelligent and Robotic Systems, 50(1), 2007, 19-39.

[7] E. Papadopoulos, I. Papadimitriou, and I. Poulakakis, Polynomial-based obstacle avoidance techniques for nonholonomic mobile manipulator systems, International Journal of Robotics and Automation, 41(4), 2005, 229-247.

[8] J.A. Yang and Y.B. Zhuang, An improved a technology optimization algorithm for solving a complex combinatorial optimization problem, Applied Soft Computing, 10(2), 2010, 653-660.

[9] X.J. Jing, Behavior dynamics based motion planning of mobile robots in uncertain dynamic environments, International Journal of Robotics and Automation, 53, 2005, 99-123.

[10] J.A. Fernández León, F.M. Tosini, G. Acosta, and H.N. Acosta, An experimental study on evolutionary reactive behaviours for mobile robots navigations, Journal of Computer Science and Technology, 5(4), 2005, 183-188.

[11] S. Kamio and H. Iba, Adaptation technique for integrating genetic programming and reinforcement learning for real robot, IEEE Transactions on Evolutionary Computation, 9(3), 2005, 318-333.

[12] X. Chen, K. Watanabe, K. Kiguchi, and K. Izumi, Path tracking based on closed-loop control for a quadruped robot in a cluttered environment, ASME Transactions on Dynamic systems, Measurement and Control, 124, 2002, 272-280.

[13] P. Graham, J. David, B.Z. Atkinson, A analytical study of grid-fault response of wind turbine, doubly-fed induction generator, IEEE Transactions on Energy Conversion, 25(4), 2010, 1081-1091.

[14] J. Morren and S.W.H.S. Haan, Three-phase short-circuit current of wind turbines with doubly fed induction generator, IEEE Transactions on Energy Conversion, 22(1), 2007, $174-180$.

[15] LI da analysis D of short circuit currenournal of Intelligent and Robotic Systems of wind turbine, doubly-fed induction generator, Proc. IEEE Conf. 1st industrial Electronics and Applications, May 24-26200-6, Singapore, 1-5.

[16] X. Zhang, D. Xu, and W. Li, Analysis of three-phase short circuit current of doubly fed induction generator, Journal of Motor and Control, 12(5), 2008, 493-497.

[17] Y. He and G. Hu, Doubly-fed asynchronous wind turbine several hot problems in parallel operation, Proceedings of the CSEE, 32(27), 2012, 1-15.

[18] Y. Zhong, S. Li, et al., Induction wind turbine LVRT measure on line overcurrent protection effect, Proceedings of the CSUEPSA, 28(06), 2016, 19-25

[19] J. Vidal, G. Abad, J. Arza, et al., The single-phase DC crowbar topologies for low voltage ride through fulfillment of high-power doubly fed induction generator based wind turbines, IEEE Transactions on Energy Conversion, 32(1), 2013, 37-49.

[20] D. Xu, W. Wang, and N. Chen, Based on the lever to protect doubly-fed wind power low voltage motor through dynamic characteristic analysis, Proceedings of the CSEE, 45(22), 2010, 29-36.

[21] D. Xiang, S. Yang, and R. Li, Grid symmetrical failure doublyfed induction generator is not to take off the network running system simulation, Proceedings of the CSEE, 18(10), 2006, 130-135.

[22] Y. Zhang, R. Tong, J. Zhao, et al., Doubly-fed wind power generator transient characteristic and low voltage across solutions, Automation of Electric Power Systems, 37(6), 2013, $7-11$.

[23] Y. He and P. Zhou, Variable speed constant frequency doublyfed asynchronous wind power system low voltage through technical review, Journal of Electrotechnics, 24(9), 2009, $140-146$.

[24] X. Zhu, L. Shi, N. Chen, et al., Considering crowbar resistance and exit time of doubly-fed wind power generator is low voltage across, Automation of Electric Power Systems, 38(18) 2010, $84-89$

[25] L. Wei, Y. Chen, and G. Chen, Doubly-fed induction wind turbines low voltage through the theoretical analysis and experimental research of control strategy, Electric Technology, 25(7), 2011, 30-36.

[26] S. Hu, D. Zhao, B. Zhao, et al., Doubly-fed wind power generator test research the characteristic of low voltage across, High Voltage Technology, 18(03), 2010, 789-795.

[27] J. Yao, Y. Liao, and H. Li, String of networking side converter of DFIG wind power system low voltage through control, Automation of Electric Power Systems, 8(6), 2010, 98-103.

[28] S. Qi, F. Li, S. He, et al., With low voltage through the ability to cluster access wind fault characteristic simulation, Power System Protection and Control, 43(14), 2015, 55-62.

[29] Z. Liu, C. Liu, and G. Li, For improving the capability of direct-drive permanent magnet low voltage through the fan power coordinated control method, Automation of Electric Power Systems, 12(3), 2015, 23-29.

[30] C. Wei, X. Song, et al., A doubly-fed induction wind generator control strategy of low voltage across, Journal of electrotechnics, 32(9), 2010, 170-175. 
[31] M. Zhang and H. Jiang, Adaptive low voltage ride-through of doubly-fed induction generators based on crowbar with a parallel dynamic resistor, Transactions of China Electrotechnical Society, 29(02), 2014, 271-278.

[32] P. Su, Y. Zhang, Based on the active type IGBT crowbar LVRT doubly-fed wind power system simulation, Power System Protection and Control, 38(23), 2010, 164-171.

[33] H. Ma, G. Yong, Y. Yang, et al., Fuzzy optimization of crowbar resistance for low-voltage ride through of doubly-fed induction generators, Proceedings of the CSEE, 32(34), 2012, 17-23.

[34] J. Yang, J.E. Fletcher, and J. O'Reilly, A series dynamic resistor based crowbar protection scheme for doubly-fed induction generator during various fault conditions, IEEE Transactions on Energy Conversion, 25(2), 2010, 422-432.

[35] I. Erlich, W. Winter, and A. Dittrich, Advanced grid requirements for the integration of wind turbines into the germane transmission system, Power Engineering Society General Meeting, Montreal, Que. Duisburg University, 2006, $1-7$.

[36] J. Li and H. Xu, Low voltage ride through technology of wind power generation system (Beijing: Machery Industry Press, 2008).

\section{Biographies}

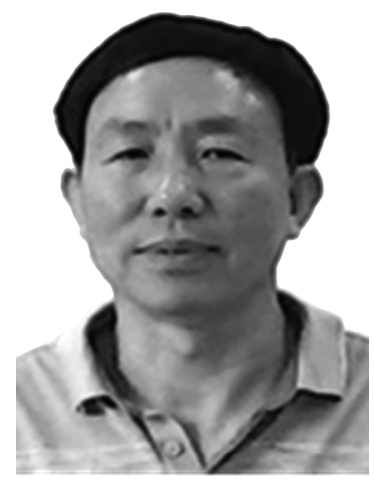

Shengqing $L i$ born in November 1961 in Yongxing, Hunan, Professor, Ph.D., enjoys the special government allowance experts, master's tutor. His research interests include distribution network power quality control, enterprise integrated electrical energy saving and micro-grid control. In recent years, he presided over the completion of the National Natural Science Foundation, the national science and technology innovation fund project and provincial key projects of more than 20. In the China Electrical Engineering Journal and other well-known publications published more than 100 papers at home and abroad, including 45 papers were included in the SCI/EI. He won the Hunan provincial science and technology progress award two prize and the three prize, the China Institute of electrical technology, science and technology award two and other awards 8 .

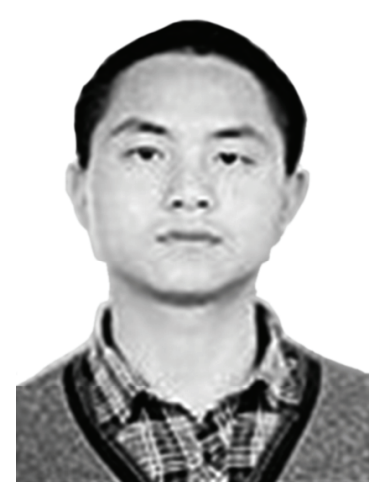

Yao Ming born in September 1991 in Shiyan, Hubei, is a master's degree candidate. His research interests are low voltage ride through technology in the wind power generation. He completed his engineering graduation from Hubei Polytechnic University, Huangshi, in the year 2013 in the Department of Electrical and Electronic Information Engineering. He has been actively involved in various research projects and published some papers at National levels Journal, the areas of research being wind power generation, automation and maintenance engineering.

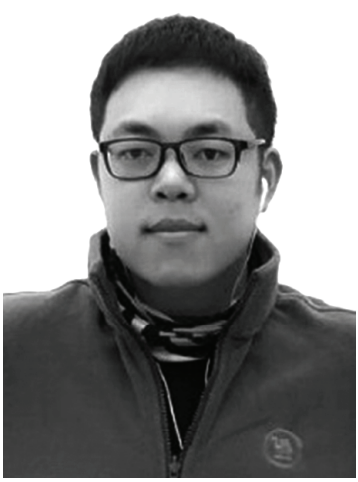

Yuwen Zhang born in January 1993 in Wuhan, Hubei, is a master's degree candidate in power electronic technology and system. He completed his engineering graduation from Huazhong University of Technology, Wenhua College, Wuhan, in the year 2015 in the Department of Electrical and Electronic Information Engineering. He has been actively involved in various research projects and published some papers at national-levels journals. His areas of research are photovoltaic power generation, automation and maintenance engineering.

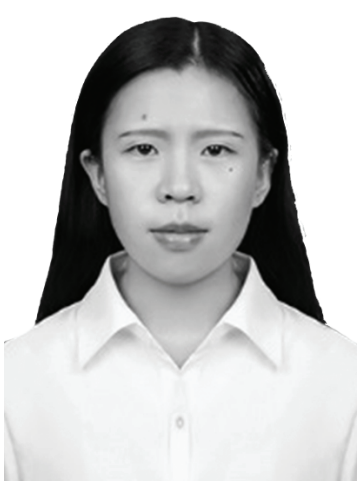

Wenfeng $W u$ born in November 1992 in Huaibei, Anhui, is a master's degree candidate. Her research interests are photovoltaic grid-connected power generation. She completed her engineering graduation from Chaohu College, Chaohu, in the year 2015 in the Department of Electrical and Electronic Information Engineering. She has been actively involved in various research projects and published some papers at national-level journals. Her areas of research are photovoltaic grid-connected power generation, automation and maintenance engineering. 